\title{
Experimental study of amorphous silicate formation
}

\author{
S. Wada ${ }^{1}$, Y. Murata ${ }^{1}$, A. T. Tokunaga ${ }^{2}$, and J. Watanabe ${ }^{1}$ \\ ${ }^{1}$ Department of Applied Physics and Chemistry, The University of Electro-Communications, Chofugaoka, Chofu, \\ Tokyo 182-8585, Japan \\ ${ }^{2}$ Institute for Astronomy, University of Hawaii, 2680 Woodlawn Dr., Honolulu, HI 96822, USA
}

Received 29 January 2003 / Accepted 13 May 2003

\begin{abstract}
Broad infrared bands at 10 and $18 \mu \mathrm{m}$ have often been observed around oxygen-rich evolved stars, and these are thought to arise from amorphous silicate dust grains. In order to study the formation mechanism of silicate dust grains, we have analyzed synthesized silicate dust analogs by reflection absorption infrared spectroscopy (RAIRS) and X-ray photoelectron spectroscopy (XPS). The dust analog was produced from $\mathrm{SiO}$ and $\mathrm{Mg}$ vapors in $\mathrm{O}_{2}$. The analyses showed that an amorphous silicate is formed at about temperature of $650 \mathrm{~K}$ through O-deficient silicate formation. However, when the substrate temperature was below $650 \mathrm{~K}$, the main product is a mixture of $\mathrm{SiO}_{x}$ and $\mathrm{MgO}$, where $1<x \leq 2$. Our experimental results indicate that temperature is an important factor for amorphous silicate formation in the circumstellar environment of oxygen-rich evolved stars.
\end{abstract}

Key words. ISM: dust, extinction - circumstellar matter - stars: mass loss - methods: laboratory

\section{Introduction}

Oxygen-rich evolved stars form silicate/metal oxide dust grains in a course of their mass loss process. Broad 10 and $18 \mu \mathrm{m}$ peaks observed in emission or absorption have been attributed to an amorphous silicate. Well-known amorphous silicates are a type of glass. Glass is a quenched liquid with silica rich composition in which $\mathrm{SiO}_{2}$ is more abundant than $\mathrm{MgO}$ and $\mathrm{FeO}$. Amorphous olivines and amorphous pyroxenes whose compositions are $2(\mathrm{MgO}+\mathrm{FeO})+\mathrm{SiO}_{2}$ and $(\mathrm{MgO}+\mathrm{FeO})+\mathrm{SiO}_{2}$ respectively have been proposed as candidate materials of amorphous silicate dust grains around oxygen-rich evolved stars. However, it is very difficult to make a glass whose composition is rich in $\mathrm{MgO}+\mathrm{FeO}$ like an olivine. Dorschner et al. (1995) produced amorphous/glassy silicate from melts by a very rapid cooling method.

Various methods have been used to synthesize silicate dust analogs with an infrared spectrum resembling that of the interstellar medium and circumstellar shells. These methods include arc melting of silicate (Dorschner et al. 1986), quenching of melts (Jäger et al. 1994; Dorschner et al. 1995), deposition from a gas mixture (Day 1979; Nuth \& Donn 1983; Wada et al. 1991; Koike \& Tsuchiyama 1992; Kaito et al. 2001), and condensation from evaporates of a laser heated silicate (Stephens \& Russell 1979; Brucato et al. 1999). These authors compare the infrared band features of their materials to the interstellar band features at 10 and $18 \mu \mathrm{m}$. They also

Send offprint requests to: $\mathrm{S}$. Wada,

e-mail: wada@e-one.uec.ac.jp compare to spectral features in the near infrared region because astronomical silicates are mixed with other dust components.

In these simulation experiments of circumstellar shells, unusual solids were often detected in condensates produced from vapors. Rietmeijer et al. (1999) synthesized condensates from a $\mathrm{Mg}-\mathrm{Fe}-\mathrm{SiO}-\mathrm{H}_{2}-\mathrm{O}_{2}$ vapor and they found amorphous grains with unique mixed "MgSiO" and "FeSiO" compositions of metastable eutectics together with oxides in the condensates. Kaito et al. (2001) observed laboratory-products from $\mathrm{Mg}$ and $\mathrm{SiO}$ smoke by high-resolution transmission electron microscope. They detected amorphous $\mathrm{MgSiO}, \mathrm{Si}$ crystallites, $\mathrm{Mg}$, $\mathrm{Mg}_{2} \mathrm{Si}, \mathrm{MgO}, \mathrm{Mg}_{2} \mathrm{SiO}_{4}$ crystal, and $\mathrm{Mg}_{2} \mathrm{SiO}_{4}$ and $\mathrm{Si}$ mixed crystal in the products.

Crystalline silicates are formed by heating of amorphous dusts after condensation. Brucato et al. (1999) determined the activation temperature for crystallization and suggested that crystalline silicates would be formed by the long term exposure of amorphous dusts to a temperature of higher than $770 \mathrm{~K}$.

A dust shell develops around a mass-loss star. It is generally thought that the highest temperature of the dust in the dust forming region corresponds to the condensation temperature of dusts. Using low resolution spectra (LRS) of Infrared Astronomical Survey (IRAS), Simpson (1991) found the temperature of inner boundaries of dust shells is $400-800 \mathrm{~K}$. This temperature is too low to form crystalline silicate in a short period of time.

In the circumstellar environment, dust grains are formed from gaseous species. Until recently, there is little experimental work concerning the formation mechanism of dusts. Our purpose is to clarify the formation process of dust by analysing the 
condensate from $\mathrm{SiO}$ and $\mathrm{Mg}$ vapors using reflection absorption infrared spectroscopy (RAIRS) and X-ray photoelectron spectroscopy (XPS).

In this paper we will attempt to address the questions of the nature of astronomical amorphous silicates and their formation mechanism by experiment and comparison to astronomical observations.

\section{Experimental}

Dust analogs were synthesized experimentally in the following manner. A Si wafer about $1 \mathrm{~cm}$ wide and $5 \mathrm{~cm}$ long was set in an apparatus which can be evacuated to under $10^{-3} \mathrm{~Pa}$. The wafer was attached to a tantalum foil that was connected to a copper electrode. Heating of the Si wafer was achieved by applying direct current to the copper electrode.

The Si wafer was heated up to $1120-1170 \mathrm{~K}$ with electric power directly in an atmosphere of oxygen. An oxygen pressure of higher than about $2 \mathrm{~Pa}$ is required to produce $\mathrm{SiO}$ vapor. However, if the oxygen pressure is too high then $\mathrm{SiO}_{2}$ forms and sticks to the surface of the $\mathrm{Si}$ wafer, thus preventing the formation of $\mathrm{SiO}$ vapor. Therefore an oxygen pressure of either 6.5 $\mathrm{Pa}$ or $13 \mathrm{~Pa}$ was used to enhance the production of $\mathrm{SiO}$.

To obtain $\mathrm{Mg}$ vapor, thin magnesium ribbons were heated in an alumina tube with a nichrome heater. The both vapors were condensed onto a tantalum substrate set at a distance of 5 or $50 \mathrm{~mm}$ apart from both vapor sources. The sample MS-1 used a distance of $50 \mathrm{~mm}$, while the samples MS-2 and MS-3 were collected with a distance of $5 \mathrm{~mm}$.

$\mathrm{SiO}$ and $\mathrm{Mg}$ were evaporated simultaneously in an oxygen atmosphere for 15-30 min. We controlled the evaporation rate of the $\mathrm{Si}$ wafer by monitoring the temperature with a pyrothermometer. However, it is difficult to control the evaporation rate of magnesium because of the low vaporization temperature of $\mathrm{Mg}$. When the temperature of the magnesium source was too high, the color of the products became bluegray (Mg metal-rich), while at lower temperatures a pale white product $\left(\mathrm{SiO}_{x}\right.$-rich) was obtained.

After synthesis, we obtained the RAIRS of the products with a Spectrum 2000 (Perkin-Elmer Co.) and the XPS with a ESCA-K1 (Shimazu Co.). RAIRS was obtained instead of an absorption spectrum because the sample was too thin to produce either a good spectrum in transmission directly or with the $\mathrm{KBr}$ pellet method.

\section{Results and discussion}

\subsection{Infrared spectra}

RAIRS is used for a measurement of a spectrum of a very thin film deposited on a metal substrate. In our experiments, we prepared sample films whose thickness did not produce an absorbance greater than 0.2 at the $9-10 \mu \mathrm{m}$ peak. The thickness was approximately $100-300 \mathrm{~nm}$. Note that the RAIRS spectra are essentially the same as the absorption spectra obtained by the $\mathrm{KBr}$ pellet method except for the reflectivity effect of the substrate metal in the case of amorphous and polycrystalline solids. The RAIRS method is described by Golden (1985).

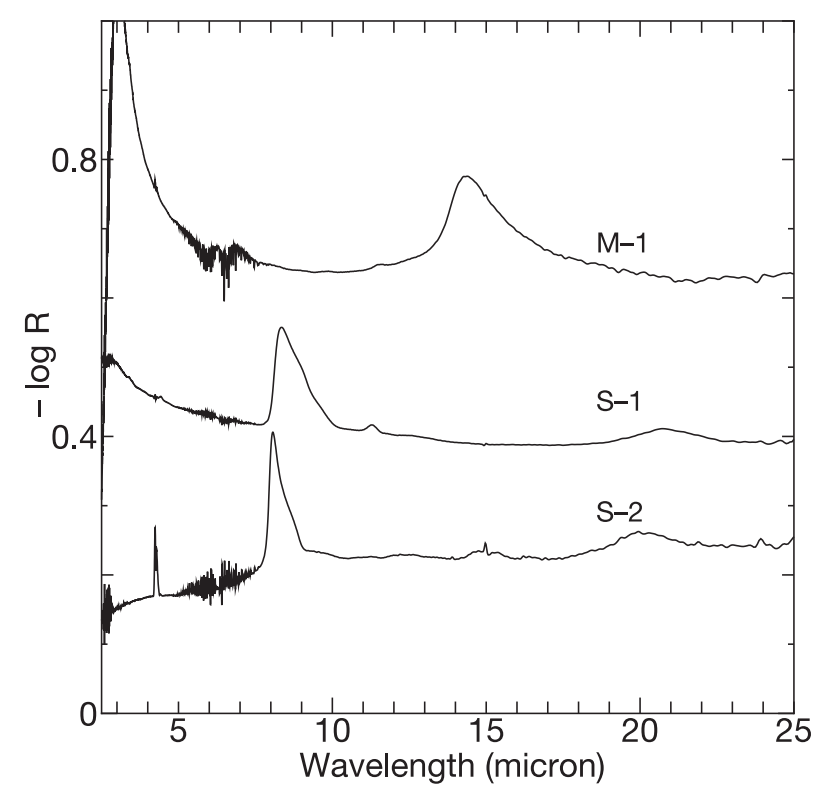

Fig. 1. RAIRS of synthetic oxides measured with an incidence angle of $60^{\circ}$. Vertical axis is $-\log R$, where $R$ is the reflectance. M-1: MgO which was formed on a cold substrate from a $\mathrm{Mg}$ vapor in $13 \mathrm{~Pa}$ of ambient $\mathrm{O}_{2}$ gas. $\mathrm{S}-1$ : a product which was formed on a cold substrate (about 300-330 K) from a $\mathrm{SiO}$ vapor in $13 \mathrm{~Pa}$ of ambient $\mathrm{O}_{2}$ gas. $\mathrm{S}-2$ : a product which was formed on a hot substrate $(\sim 650 \mathrm{~K})$ from a $\mathrm{SiO}$ vapor in $6.5 \mathrm{~Pa}$ of ambient $\mathrm{O}_{2}$ gas. Sharp peaks at $4.2 \mu \mathrm{m}$ and many fine peaks $\sim 6 \mu \mathrm{m}$ are caused by atmospheric $\mathrm{CO}_{2}$ and $\mathrm{H}_{2} \mathrm{O}$, respectively.

RAIRS of samples are shown in Figs. 1 and 2. The sample $\mathrm{S}-1$ is a condensate collected on the cold substrate (300$330 \mathrm{~K}$ ), which was made from the $\mathrm{SiO}$ vapor only. Peaks appear at 8.2, 11.2 and $20.7 \mu \mathrm{m}$ as shown in Fig. 1. The sample $\mathrm{S}-2$ is a condensate from $\mathrm{SiO}$ vapor on a hot substrate at $650 \mathrm{~K}$. In the spectrum, peaks are observed at 8 and $20 \mu \mathrm{m}$, however there is no peak in the $11-17 \mu \mathrm{m}$ spectral region.

It is known that in the absorption spectrum of $\mathrm{SiO}_{2}$ three TO modes give rise to absorption peaks; asymmetric stretching of O-Si-O (AS, $\sim 9 \mu \mathrm{m}$ ), symmetrical stretching of the oxygen atom along a line bisecting the axis formed by the two Si atoms ( $\mathrm{SS}, 12.5 \mu \mathrm{m}$ ), and rocking of the oxygen atom around the axis connecting the two silicon atoms ( $\mathrm{R}, 21.5 \mu \mathrm{m})$. More precisely, the AS is composed of two modes. In one stretching mode neighboring oxygen atoms move in phase $\left(\mathrm{AS}_{1}, 9.30 \mu \mathrm{m}\right)$ and in the other mode they move out of phase each other $\left(\mathrm{AS}_{2}\right.$, $8.70 \mu \mathrm{m})$ (Trchová et al. 1997).

Moreno et al. (1997) analyzed infrared spectra of a $\mathrm{SiO}_{2}$ film of various thickness. The 9-10 $\mu \mathrm{m}$-band feature of $\mathrm{SiO}_{2}$ shows complicated variations depending on incidence angle and the film thickness. Therefore we prepared samples with a constant film thickness and measured RAIRS spectra with a fixed incidence angle of $60^{\circ}$ or $75^{\circ}$. These angles were chosen because the best spectra were obtained at these angles; the spectra were more noisy at higher angles.

In the infrared transmission absorption spectra of solid$\mathrm{SiO}_{x}(1<x<2)$, the AS peak usually appears at a longer wavelength than that of $\mathrm{SiO}_{2}$. The peak moves to the shorter wavelength region with increasing concentration of oxygen 


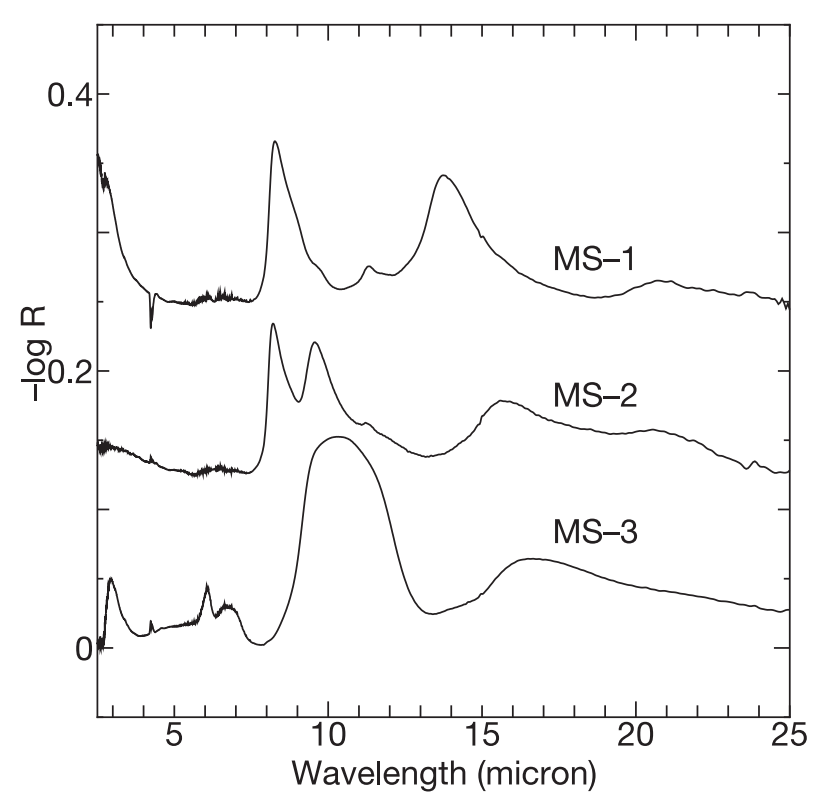

Fig. 2. RAIRS of products from $\mathrm{Mg}$ and $\mathrm{SiO}$ measured with an incidence angle of $75^{\circ}$ (MS-1) and $60^{\circ}$ (MS-2 and MS-3). MS-1: a product formed on a cold substrate. MS-2: a product formed on a hot $(650 \mathrm{~K})$ substrate. MS-3: a product formed on a hot $(650 \mathrm{~K})$ substrate.

(Nakamura et al. 1984). Another index for the oxygen concentration of $\mathrm{SiO}_{x}$ is the $\mathrm{SS}$ peak. The peak at $12.5 \mu \mathrm{m}$ peak in $\mathrm{SiO}_{2}$ spectrum is not observed in the $\mathrm{SiO}_{x}$ produced in vacuum, instead, a small peak appears at $11.4 \mu \mathrm{m}$.

The sample $\mathrm{S}-2$ appears to be $\mathrm{SiO}_{2}$ from its peak wavelength, although the $12.5 \mu \mathrm{m}$ peak is not seen in the RAIRS. On the other hand, S-1 is not oxidized enough. A $11.2 \mu$ m peak in the RAIRS of S-1 corresponds to the $11.4 \mu$ m peak of $\mathrm{SiO}_{x}$ in the transmission infrared spectrum. These results indicate that $\mathrm{SiO}_{x}$ is completely oxidized if the substrate temperature is $650 \mathrm{~K}$.

In the spectrum of $\mathrm{MgO}$ crystal, peaks caused by $\mathrm{LO}$ and TO modes appear at $13.9 \mu \mathrm{m}$ and $24.9 \mu \mathrm{m}$, respectively (Farmer 1974). A RAIRS of MgO sample is presented in Fig. 1, $\mathrm{M}-1$. The sample was produced from a vapor of $\mathrm{Mg}$ in a $13 \mathrm{~Pa}$ atmosphere of $\mathrm{O}_{2}$. A peak is observed at 14.3-14.7 $\mu \mathrm{m}$ (LO) in the RAIRS, however the TO peak is not observed in the wavelength region of our measurements. As mentioned above, metallic $\mathrm{Mg}$ is often contained in the products. This is caused by the high evaporation rate of $\mathrm{Mg}$.

$\mathrm{SiO}$ and $\mathrm{Mg}$ were evaporated simultaneously and condensed on substrates with different temperatures. The sample which was formed on a cold substrate is presented in Fig. 2 (MS-1). Clearly, MS-1 is a superposed spectrum of S-1 and M-1. This means that the sample is a mixture of $\mathrm{SiO}_{x}$ and $\mathrm{MgO}$.

MS-2 and MS-3 were condensed on a $650 \mathrm{~K}$ substrate and the spectra are presented in Fig. 2. In the spectrum of MS-2 two bands appear in $8-9.5 \mu \mathrm{m}$. These peak wavelengths correspond to those of $\mathrm{AS}_{1}$ and $\mathrm{AS}_{2}$ of $\mathrm{SiO}_{2}$. However, the wavelength of the peak seen at $15.5 \mu \mathrm{m}$ is longer than that of $\mathrm{MgO}$. We infer that phase separation occurred in MS-2 and the structure of $\mathrm{MgO}$ was modified due to a chemical reaction with $\mathrm{SiO}_{x}$. The peaks in $8-9 \mu \mathrm{m}$ should be affected by the reaction.

Two broad bands appear at $10 \mu \mathrm{m}$ and $16.5-17 \mu \mathrm{m}$ in the RAIRS of MS-3. That indicates a new material form in MS-3. This spectrum has some resemblance to spectra often observed around evolved stars.

MS-2 and MS-3 were synthesized under the same experimental condition. In spectra of samples produced about 520-570 K, a peak around $15.5 \mu \mathrm{m}$ appeared with or without the $\sim 14 \mu \mathrm{m}-\mathrm{MgO}$ band and a modified $9 \mu \mathrm{m}$ peak was often observed. This means that a chemical reaction begins to occur in this temperature range. The temperature dependence of the reaction is a future problem.

In the next section we discuss the nature of the composition differences between MS-2 and MS-3. A temperature of about $650 \mathrm{~K}$ or higher was found to be necessary temperature to form silicate material.

Small peaks in the MS-3 are caused by absorption of $\mathrm{H}_{2} \mathrm{O}$ (3 $\mu \mathrm{m}$ and $6 \mu \mathrm{m}$ ) in the air. A peak at $7 \mu \mathrm{m}$ is often observed in spectra of $\mathrm{Mg}$-containing sample, and this is caused from carbonate absorption which is produced by a reaction with $\mathrm{CO}_{2}$ in air.

It should be noted that the RAIRS spectra shown in Figs. 1 and 2 cannot be directly compared to absorption spectra because the RAIRS spectra depend critically on the incidence angle.

\subsection{X-ray photoelectron spectroscopy}

XPS measures energy of the photoelectron ejected from atoms upon irradiation by X-rays. From XPS we can obtain information about the chemical bonding of the element in the material. In our XPS experiments we used $\operatorname{MgK} \alpha$ as source of the excitation. The $\mathrm{C} 1 \mathrm{~s}$ peak of carbon was used as an internal reference peak. We corrected the observed binding energies by using the C 1s peak $(284.4 \mathrm{eV})$ which was contained in our samples as a contaminant.

Guittet et al. (2001) discussed the binding energy of Si 2p and $\mathrm{O} 1 \mathrm{~s}$ in mixed oxides. They calculated the Si 2p-binding energy in mixed oxides using a linear combination of charge of silicon atom, the Madelung energy (Coulomb force and structure of oxides), and the relaxation energy (final state after electron emission). Their calculation agreed well with their experimental values of a crystalline olivine, $\mathrm{ZrSiO}_{4}(101.8 \mathrm{eV})$ and $\mathrm{SiO}_{2}(103.4 \mathrm{eV})$. The binding energy of silicon $(\mathrm{Si})$ and that of a silicide $\left(\mathrm{Mg}_{2} \mathrm{Si}\right)$ are expected to be lower than these values because of the charge of silicon atom. The binding energies are reported as 99.7 eV for silicon (Trchová et al. 1997) and $98.5 \mathrm{eV}$ for silicide (An et al. 1995).

Since $\mathrm{SiO}_{x}(1<x \leq 2)$ are very important materials for industrial applications, many XPS studies have been performed. The Si $2 p$ peak of the low oxidation state appears in the lower energy region than that of $\mathrm{SiO}_{2}$. The difference of binding energy of $\mathrm{Si}(\mathrm{IV}), \mathrm{Si}(\mathrm{III}), \mathrm{Si}(\mathrm{II}), \mathrm{Si}(\mathrm{I})$, and $\mathrm{Si}(0)$, in which IV, III, II, I, 0 is the oxidation number of silicon, was reported to be about $1 \mathrm{eV}$ by Barranco et al. (2001). In particular they reported the binding energies to be $\mathrm{Si}(\mathrm{IV}): 103 \mathrm{eV}, \mathrm{Si}(\mathrm{III}): 102 \mathrm{eV}$, 

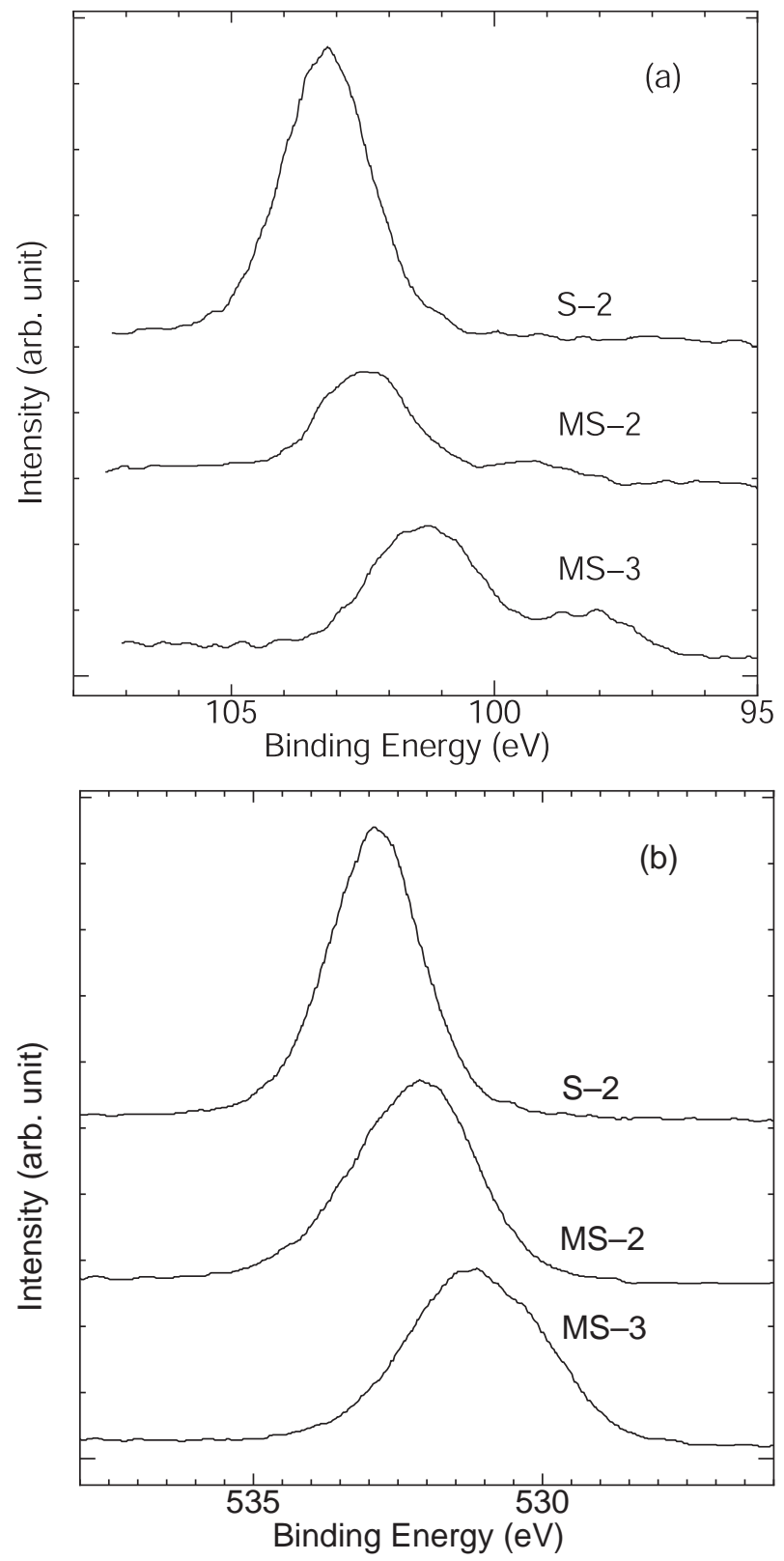

Fig. 3. a) XPS spectra of $\mathrm{Si} 2 \mathrm{p}$ of $\mathrm{S}-2$, MS-2, and MS-3. b) XPS spectra of O 1s of S-2, MS-2, and MS-3.

$\mathrm{Si}(\mathrm{II}): 101 \mathrm{eV}, \mathrm{Si}(\mathrm{I}): 100 \mathrm{eV}, \mathrm{Si}(0): 99 \mathrm{eV}$. Barranco et al. (2001) made a condensate from $\mathrm{SiO}$ vapor in ultra high vacuum. The composition was $\mathrm{SiO}_{1.3}$ and it was composed of $\mathrm{Si}(\mathrm{I})$ and $\mathrm{Si}(\mathrm{III})$ as a result of oxidation-reduction reaction of $\mathrm{SiO}$.

Figure 3a shows Si $2 p$ spectra of XPS for samples of S-2, MS-2, and MS-3. Only one peak appears at $103.2 \mathrm{eV}$ in S-2. The feature is smooth and symmetrical. The peak of S-2 coincides with the binding energy of $\mathrm{SiO}_{2}(103 \mathrm{eV})$. The result agrees with RAIRS measurement.

Two peaks are detected in MS-3. The main peak is found at $101.3 \mathrm{eV}$ and a broad small peak is found at $98.0 \mathrm{eV}$. The peak of an olivine, $\mathrm{ZrSiO}_{4}$ presented by Guittet et al. (2001) is very close to the $101 \mathrm{eV}$ peak. However the peak of MS-3 is located on the lower energy side. We tentatively assign MS-3 to an O-deficient silicate. The peak at $98.0 \mathrm{eV}$ coincides with the silicide peak.

MS-2 shows a maximum at $102.5 \mathrm{eV}$ with a shoulder at $103.2 \mathrm{eV}$. The shoulder at $103.2 \mathrm{eV}$ indicates the presence of $\mathrm{SiO}_{2}$. The peak of the MS-2 occurs at higher energy than that of MS-3. We think that the material and the peak at $99.0 \mathrm{eV}$ corresponds to the peak of $\mathrm{Si}(0)$.

Full width at half maximum (FWHM) of peaks depends on the variety of the chemical bonds of Si. The FWHM of the main peak of S-2, MS-2, and MS-3 is 1.9, 2.1, and $2.5 \mathrm{eV}$, respectively. This indicates that there are more kinds of Si bonds in MS-3 than S-2 and MS-2.

Guittet et al. (2001) reported that binding energies of $\mathrm{O} 1 \mathrm{~s}$ are $532.7 \mathrm{eV}\left(\mathrm{SiO}_{2}\right)$ and $531.3 \mathrm{eV}\left(\mathrm{ZrSiO}_{4}\right)$, respectively. The binding energies of oxygen shown in Fig. $3 \mathrm{~b}$ are measured at 532.9 (S-2), 532.1 (MS-2), and $531.1 \mathrm{eV}$ (MS-3). The values of full width at half maximum are 1.9 (S-2), 2.5 (MS-2), and $2.9 \mathrm{eV}$ (MS-3). The binding energy is also matched with $\mathrm{SiO}_{2}$ (S-2). The peak of MS-3 is composed of two peaks at least. Apparently, the binding energy at the maximum of the peak in MS-3 is very close to that of olivine. The O 1s-peak of MS-2 is also an intermediate value between S-2 and MS-3.

Note that the oxidation numbers of silicon atom are II in $\mathrm{SiO}$ molecule, and 0 in solid silicon and silicide, $\mathrm{Mg}_{2} \mathrm{Si}$. The presence of solid silicon and silicide appearing in MS-2 and MS-3 means that silicon atom is reduced from II to 0 . On the other hand, the oxidation number of silicon atom is IV in $\mathrm{SiO}_{2}$ and silicates. The presence of these compounds means that silicon atom is oxidized from II to IV. In other words, reactions of oxidation and reduction of silicon atoms occurred in our samples.

We performed a depth analysis of Si 2p of MS-3. The binding energy of the main peak seems to be slightly shifted to higher energy side. The peak intensity of silicide decreases with depth, as shown in Fig. 4. Most likely we are observing that the material changes to silicate as we go deeper into the sample.

\subsection{Silicate formation}

Based on the preceding analysis, we present the following mechanism for the formation of MS-3, as compared with that of MS-2. RAIRS of MS-3 shown in Fig. 2 is similar to emission and absorption spectra of amorphous silicate dusts around oxygen-rich evolved stars. The product of MS-3 is an amorphous silicate, since the $10 \mu \mathrm{m}$ feature of RAIRS corresponding to asymmetric stretching of O-Si-O is broad and the wavelength is shifted to the longer side than that of $\mathrm{SiO}_{2}$.

Both samples of MS-2 and MS-3 were produced with the same experimental conditions with a substrate temperature of $650 \mathrm{~K}$. In MS-3, the deposit reacted rapidly to form O-deficient amorphous silicates, $\mathrm{Mg}_{2} \mathrm{SiO}_{4-x}$ or $\mathrm{MgSiO}_{3-x}(x \geq 0)$ (we don't know the ratio of $\mathrm{Mg} / \mathrm{Si}$ in the samples). At the same time, a small amount of reduced silicon $\left(\mathrm{Mg}_{2} \mathrm{Si}\right.$ and $\left.\mathrm{Si}\right)$ is also produced. As mentioned above, MS-2 is a mixture of $\mathrm{SiO}_{2}, \mathrm{SiO}_{x}$, a product reacted from $\mathrm{SiO}-\mathrm{MgO}$ and silicon. It is thought that gases of $\mathrm{Mg}$ and $\mathrm{SiO}$ were not mixed 


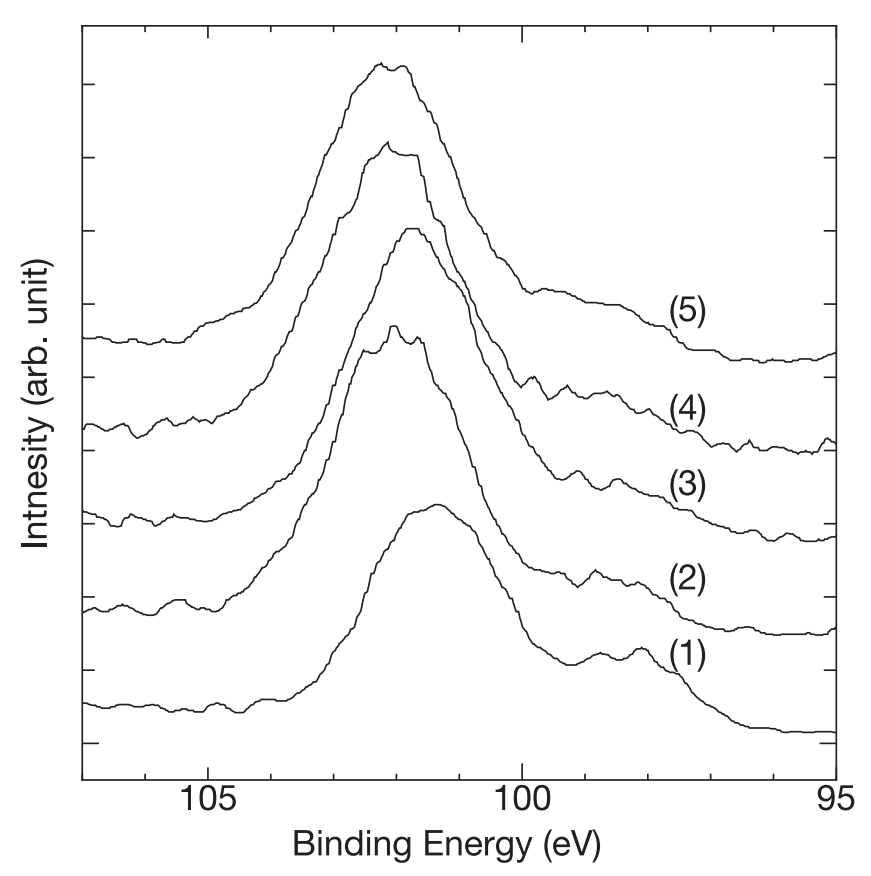

Fig. 4. Variation of XPS spectra of Si $2 p$ with depth. Total minutes for milling by Ar ions are (1) $0 \mathrm{~min}$ (surface), (2) $4 \mathrm{~min}$, (3) $8 \mathrm{~min}$, (4) $12 \mathrm{~min}$, and (5) $16 \mathrm{~min}$.

well and/or the ambient $\mathrm{O}_{2}$ pressure was slightly higher than in the experimental conditions of MS-3.

The formation of MS-3 starts from O-deficient silicates, i.e. $\mathrm{Mg}_{2} \mathrm{SiO}_{4-x}$ or $\mathrm{MgSiO}_{3-x}(x>0)$, containing many oxygen vacancies. The structure of the $\mathrm{O}$-deficient silicates is amorphous due to the $\mathrm{O}$ vacancies. The $\mathrm{O}$-deficient silicates are considered to be less stable than completely oxidized silicates, such as $\mathrm{Mg}_{2} \mathrm{SiO}_{4}$ and $\mathrm{MgSiO}_{3}$.

The O-deficient silicate, for examples, $\mathrm{Mg}_{2} \mathrm{SiO}_{4-x}$ is more unstable than $\mathrm{Mg}_{2} \mathrm{SiO}_{4-x^{\prime}}$ for $x>x^{\prime}$. Thus, when the second layer of $\mathrm{Mg}_{2} \mathrm{SiO}_{4-x}$ is formed on the first layer, a small amount of $\mathrm{O}$ atoms is transferred from the overlayer to the underlayer and a part of vacancies in the underlayer is occupied by $\mathrm{O}$ atoms. Next, the third layer is deposited and $\mathrm{O}$ atoms migrate from the second and the third layer to the first and the second layer, respectively. Further processes continue and the oxygen migration to the adjacent underlayer always occurs in every layer for each step.

Then, the $x$ value of $\mathrm{Mg}_{2} \mathrm{SiO}_{4-x}$ and $\mathrm{MgSiO}_{3-x}$ decreases with depth and silicide of $\mathrm{Mg}_{2} \mathrm{Si}$ and silicon is formed near the surface. This formation mechanism of MS-3 is supported by variation of XPS spectra of Si $2 p$ with depth shown in Fig. 4. In addition to the decrease of the peak intensity corresponding to $\mathrm{Mg}_{2} \mathrm{Si}$ with depth, the binding energy of the main peak is slightly shifted to higher binding energy side. That is, Si atoms are more oxidized with depth due to the $\mathrm{O}$ atom migration. The substrate temperature of $650 \mathrm{~K}$ is necessary for the $\mathrm{O}$ atom diffusion to the adjacent underlayer. As a result, silicate forms as an end member of oxidized product and silicide or silicon forms as an end member of reduced product.

After receiving $\mathrm{O}$ atoms from the overlayer, however, the amorphous structure is not transformed to the crystalline state, because of the registration of the amorphous structure due to the overlayer. Thus, the underlayer silicates keep their amorphous structure.

\subsection{Astronomical implications}

Broad 10 and $18 \mu \mathrm{m}$ bands have been observed in emission and absorption around oxygen-rich evolved stars. Both bands are usually attributed to amorphous silicate dusts. Various features were noted in the $8-14 \mu \mathrm{m}$ spectral range by Little-Marenin \& Little (1990), and they classified them into groups (7 groups for M Mira variables), 6 groups for oxygen-rich AGB stars, and 6 groups for red giants (Speck et al. 2000). About 32\% of the M Mira variables show the standard silicate feature (denoted as "Sil" by Little-Marenin \& Little 1990). The Sil feature extends from about $8-14 \mu \mathrm{m}$ with a peak at $9.8 \pm 0.2 \mu \mathrm{m}$. They reported a broad 18 micron peak that is often but not always observed with the Sil bands.

In some groups, a $11 \mu \mathrm{m}$ and a $13 \mu \mathrm{m}$ bands are observed in addition to the $10 \mu \mathrm{m}$ peak. The $\sim 12 \mu \mathrm{m}$ peak in M Mira variables has been attributed to alumina grain (Onaka et al. 1989). Though the $11 \mu \mathrm{m}$ peak have been attributed to crystalline silicate (olivine; Little-Marenin \& Little 1990), recently amorphous alumina grains was proposed as the candidate material for the broad $11 \mu \mathrm{m}$ peak (Miyata et al. 2000; Begemann et al. 1997). On the other hand, a spinel which is a double oxide of aluminum and magnesium was proposed as the carrier of the $13 \mu \mathrm{m}$ band (Fabian et al. 2001).

Another oxide, $\mathrm{Mg}_{0.1} \mathrm{Fe}_{0.90} \mathrm{O}$, was proposed as a carrier of the $19.5 \mu \mathrm{m}$ feature which is accompanied by 13 and $17 \mu \mathrm{m}$ features of oxygen-rich stars (Posch et al. 2002). Authors suggested the existence of a shell dominated by oxide dusts not accompanied by silicate dust around the circumstellar space. This implies that oxides formed under different physical condition from amorphous silicate dust.

In the present work, we focus on the dust analog which emits Sil-like spectrum. Our synthesized material MS-3 shows a Sil-like spectrum, although our spectrum was obtained by RAIRS. Gail \& Sedlmayr (1999) discussed processes of dust formation around an $\mathrm{M}$ star. They reported that olivine, periclase $(\mathrm{MgO})$, and a small fraction of quartz $\left(\mathrm{SiO}_{2}\right)$ are formed in the outflow. Kozasa \& Sogawa $(1997,1998)$ and Sogawa \& Kozasa (1999) calculated the condensation temperature and crystallized volume fraction of silicate dust formation of a typical aged star with and without $\mathrm{Al}_{2} \mathrm{O}_{3}$ as a function of distance for a given mass-loss rate. Their results show that the condensation temperature without nuclei is ranging from $\sim 900 \mathrm{~K}$ (mass-loss rate $=4 \times 10^{-5} M_{\odot} / \mathrm{yr}$ ) to $\sim 400 \mathrm{~K}$ (mass-loss rate $\left.=1 \times 10^{-6} M_{\odot} / \mathrm{yr}\right)$.

Onaka et al. (2002) observed the infrared spectrum of Z Cyg over an entire light cycle. The object is an oxygen-rich Mira variable star. The infrared spectral features indicate that the dust is amorphous during the light cycle. However, ratios of the peak height of 10 to the $18 \mu \mathrm{m}$ changes during a light cycle. They attributed it to a change of dust-temperature and they estimated the highest dust temperature to be $700 \pm 100 \mathrm{~K}$. Simpson (1991) also assumed the temperature of inner dust 
shell is in the range 400-800 $\mathrm{K}$. The dust formation in these objects occurred at a lower temperature than those assumed previously.

The chemical composition (metal composition), oxidation degree (the ratio of oxygen to metals), mineral compositions, amorphous or crystalline, have been discussed regarding dust formation. Oxygen-deficient materials have been proposed as a candidate material. Nuth \& Donn (1983) made condensates from $\mathrm{SiO}$ and $\mathrm{Mg}$ in ambient $\mathrm{H}_{2}$ and Suzuki et al. (2000) made a condensate from $\mathrm{SiO}$ and $\mathrm{Mg}$ or $\mathrm{Fe}$ gas under vacuum. We have made a $\mathrm{SiO}$-condensate in vacuum and discussed its infrared feature (Wada et al. 1991). We think that dusts in circumstellar spaces have various degrees of oxidation.

In the present work, we synthesized dust analogs in an $\mathrm{O}_{2}$ atmosphere. Silicates, oxides, silicide, silicon are found to be possible products. At about $650 \mathrm{~K}$, an amorphous silicate was formed from vapors of $\mathrm{SiO}$ and $\mathrm{Mg}$ in our experiments. Silicide was observed in the surface region of the products. The amorphous silicate was formed by oxidation-reduction reaction in O-deficient silicate $\left(\mathrm{Mg}_{2} \mathrm{SiO}_{4-x}, \mathrm{MgSiO}_{3-x}\right)$. On the other hand, oxides were main products on a cold substrate whose temperature was lower than $650 \mathrm{~K}$. However, as oxidation did not proceed sufficiently, the product contained $\mathrm{SiO}_{x}$ and metallic $\mathrm{Mg}$. Our experiments indicate that temperature and ambient $\mathrm{O}_{2}$ pressure are important factors as to whether the amorphous silicate forms or oxides form.

The net reaction of the $\mathrm{Mg}$-silicate (olivine) is expressed as:

$2 \mathrm{Mg}+\mathrm{SiO}+3 \mathrm{H}_{2} \mathrm{O} \rightarrow \mathrm{Mg}_{2} \mathrm{SiO}_{4}$ (olivine) $+3 \mathrm{H}_{2}$.

This expression follows that of Ferrarotti \& Gail (2001). However we removed $\mathrm{Fe}$ in the equation since we did not include Fe in our experiment for simplicity.

There are of course differences in our experiment and the dust formation in circumstellar space. As discussed above, oxidizing species in the circumstellar environment is different from $\mathrm{O}_{2}$, for example, $\mathrm{H}_{2} \mathrm{O}$, atomic oxygen, and $\mathrm{OH}$ radical. Therefore, the concentration of oxygen in the products would differ from those obtained in our experiment.

At present we do not understand completely the chemical composition $(\mathrm{Mg} / \mathrm{Si} / \mathrm{O})$ of our products and that of circumstellar dusts of evolved stars. Studies on the chemical composition and the chemical structure of the material and other pathways to silicate formation are future problems.

\section{Summary}

We studied the silicate formation mechanism experimentally. Our experiments indicate following.

1. With a substrate temperature under $650 \mathrm{~K}$, oxides, $\mathrm{MgO}$ and $\mathrm{SiO}_{x}$, are the main products.

2. At about $650 \mathrm{~K}$, amorphous silicate is formed from vapors of $\mathrm{Mg}$ and $\mathrm{SiO}$ in $\mathrm{O}_{2}$ atmosphere.

3. XPS showed that amorphous silicate formed by a chemical reaction of oxidation-reduction of O-deficient silicate.
4. It is suggested by our experiments that around oxygenrich mass loss stars amorphous silicate is formed through O-deficient silicate when the dust temperature is about $650 \mathrm{~K}$ or higher.

Acknowledgements. Part of this work was supported by Grant-in-Aid for Scientific Research (B)(2) project number 11440063 from Japan Society for the Promotion of Science.

\section{References}

An, K. S., Park, R. J., Kim, J. S., et al. 1995, J. Appl. Phys., 78, 1151 Barranco, A., Mejías, J. A., Espinós, J. P., et al. 2001, J. Vac. Sci. Technol. A., 19, 136

Begemann, B., Dorschner, J., Henning, Th., et al. 1997, ApJ, 476, 199

Brucato, J. R., Colangeli, L. Mennella, V., et al. 1999, A\&A, 348, 1012

Day, K. L. 1979, Ap\&SS, 65, 173

Dorschner, J., Friedemann, C., Gürtler, J., et al. 1986, MNRAS, 218, 37

Dorschner, J., Begemann, B., Henning, Th., et al. 1995, A\&A, 300, 503

Fabian, D., Posch, Th., Mutschke, H., et al. 2001, A\&A, 373, 1125

Farmer, V. C. 1974, The infrared spectra of minerals, ed. V. C. Farmer (Mineralogical Society), 184

Ferrarotti, A. S., \& Gail, H.-P. 2001, A\&A, 371, 133

Gail, H. P., \& Sedlmayr, E. 1999, A\&A, 347, 594

Golden, W. G. 1985, in Fourier-Transform Infrared Spectroscopy, ed.

J. R. Ferraro, \& L. J. Basile (Florida: Academic Press Inc.), 4, 315

Guittet, M. J., Crocombette, J. P., \& Gautier-Soyer, M. 2001, Phys. Rev. B, 63, 125117

Jäger, C., Mutschke, H., Begemann, B., et al. 1994, A\&A, 292, 641

Kaito, C., Ojima, Y., Kido, O., et al. 2001, M\&PSA, 36, A91

Koike, C., \& Tsuchiyama, A. 1992, MNRAS, 255, 248

Kozasa, T., \& Sogawa, H. 1997, Ap\&SS, 251, 165

Kozasa, T., \& Sogawa, H. 1998, Ap\&SS, 264, 654

Little-Marenin, I. R., \& Little, S. J. 1990, AJ, 99, 1173

Miyata, T., Kataza, H., Okamoto, Y., et al. 2000, ApJ, 531, 917

Moreno, J. A., Garrido, B., Samitier, J., et al. 1997, J. Appl. Phys., 81, 1933

Nakamura, M., Mochizuki, Y., Usami, K., et al. 1984, Solid State Comm., 50, 1079

Nuth, J. A., \& Donn, B. 1983, J. Geophys. Res. Suppl., 88, A847

Onaka, T., de Jong, T., \& Willems, F. J. 1989, A\&A, 218, 169

Onaka, T., de Jong, T., \& Yamamura, I. 2002, A\&A, 388, 573

Posch, Th., Kerschbaum, F., Mutschke, H., et al. 2002, A\&A, 393, L7

Rietmeijer, F. J. M., Nuth III, J. A., \& Karner, J. M. 1999, ApJ, 527, 395

Simpson, J. P. 1991, ApJ, 368, 570

Sogawa, H., \& Kozasa, T. 1999, ApJ, 516, L33

Speck, A. K., Barlow, M. J., Sylvester, R. J., et al. 2000, A\&AS, 147, 437

Stephens, J. R., \& Russell, R. W. 1979, ApJ, 228, 780

Suzuki, N., Kimura, S., Nakada, T., et al. 2000, Meteoritics \& Planetary Sci., 35, 1269

Trchová, M., Zemek, J., \& Jurek, K. 1998, J. Appl. Phys., 82, 3519

Wada, S., Sakata, A., \& Tokunaga, A. T. 1991, ApJ, 375, L17 